\title{
Sundowning in Dementia: Clinical Relevance, Pathophysiological Determinants, and Therapeutic Approaches
}

Marco Canevelli*, Martina Valletta, Alessandro Trebbastoni, Giuseppe Sarli,
Fabrizia D'Antonio, Leonardo Tariciotti, Carlo de Lena and Giuseppe Bruno

Department of Neurology and Psychiatry, "Sapienza" University of Rome, Rome, Italy

Sundowning means the emergence or worsening of neuropsychiatric symptoms (NPS) in the late afternoon or early evening. This syndrome has been recognized since a long time in the field of dementing illnesses and is well known among most of health-care providers involved in the assistance of people with dementia. Indeed, it represents a common manifestation among persons with dementia and is associated with several adverse outcomes (such as institutionalization, faster cognitive worsening, and greater caregiver burden). Its occurrence and phenotypic characteristics may be influenced by diverse neurobiological, psychosocial, and environmental determinants. Moreover, it may pose diagnostic challenges in relation to other common causes of behavioral disruptions. Beside these considerations, this phenomenon has so far drawn limited clinical and scientific interest compared to other specific NPS occurring in dementias, as indicated by the lack of commonly agreed definitions, specific screening/assessment tools, and robust estimates on its prevalence. Accordingly, no randomized controlled trial specifically investigating the effectiveness of pharmacological and non-pharmacological strategies in managing this condition among demented patients has been yet conducted. In the present narrative review, we present and discuss available evidence concerning sundowning occurring in people with dementia. A special focus is given to its definitions, pathophysiological determinants, and clinical relevance, as well as to the clinical and therapeutic approaches required for its management in the daily practice.

Keywords: sundowning, sundown syndrome, behavioral disruptions, neuropsychiatric symptoms, dementia, behavioral and psychological symptoms of dementia, circadian rhythm

\section{INTRODUCTION}

Accepted: 19 December 2016 Published: 27 December 2016

Citation:

Canevelli $M$, Valletta $M$, Trebbastoni A, Sarli G, D'Antonio F, Tariciotti L, de Lena $C$ and Bruno $G$ (2016) Sundowning in Dementia:

Clinical Relevance,

Pathophysiological Determinants, and Therapeutic Approaches. Front. Med. 3:73. doi: 10.3389/fmed.2016.00073
Neuropsychiatric symptoms (NPS) represent core features of dementias, occurring in the overwhelming majority of cases and being highly burdening for patients and families. Moreover, they constitute a major determinant for health-care expenditures $(1,2)$. The clinical and research approach to these manifestations is extremely challenging. Indeed, NPS are characterized by a marked interindividual variability. Their prevalence and severity change over the course of the disease. Moreover, multiple interacting variables and pathophysiological mechanisms may influence their occurrence and phenotypic expression (3). These aspects have been frequently hindering the application of standardized clinical and analytic approaches to NPS, as well as the identification of targeted pharmacological interventions (4). 
A condition that properly mirrors the relevant complexity of the neuropsychiatric manifestations of dementia is represented by the "sundown syndrome," that is, the emergence or worsening of NPS in the late afternoon or early evening. This entity has been recognized since a long time in the field of dementing illnesses (5) and is well known among most of health-care providers involved in the assistance of persons with dementia. Curiously, even many ordinary people who have personal experiences or acquired knowledge about neurodegenerative diseases are aware of this "bizarre" phenomenon. Nevertheless, the sundown syndrome has so far drawn limited clinical and scientific interest compared to other specific NPS and behavioral disturbances occurring in dementias (e.g., apathy, depression, psychotic symptoms). As a proof, the available data concerning its prevalence (mostly obtained in institutional/residential settings) are scarce and markedly discordant in the literature. Moreover, no randomized controlled trial (RCT) specifically investigating the effectiveness of pharmacological and non-pharmacological strategies in managing this condition among demented patients has been yet conducted. Several aspects may account for this low attention, such as the lack of commonly agreed definitions, the absence of specific screening and assessment tools and the multiplicity of factors that may trigger or affect its occurrence.

In the present narrative review, we present and discuss the evidence collected so far concerning the clinical characteristics and relevance of the sundown syndrome, its pathophysiological determinants and its pharmacological and non-pharmacological management. Special attention will be also dedicated to the methodological issues that are still limiting and hampering the clinical and research approach to this phenomenon.

\section{DEFINITION OF SUNDOWNING}

A clear and univocal definition of the sundown syndrome (often referred to as "sundowning") has not been yet achieved. These terms are broadly used to describe a set of NPS occurring in elderly patients at and/or after the time of sunset. Diverse conceptual aspects have hampered the formulation of a unique definition. First of all, some authors have restricted the adoption of the sundowning construct to only people with dementia, whereas others have described this phenomenon also among cognitively intact elderly individuals (even if with lower frequency) (6). A second element of heterogeneity relies in the clinical manifestations included in the sundown syndrome. Indeed, some definitions refer to the onset or worsening of specific NPS [agitation in particular (7)], while others more widely include any behavioral and psychological disturbance. In this regard, these behaviors may consist of a wide variety of symptoms such as anxiety, agitation, aggression, pacing, wandering, resistance, screaming, yelling, visual and auditory hallucinations, and so forth (8). Several conceptualizations also incorporate the exacerbation of cognitive symptoms and confusion (7), thus rendering more subtle the distinction with delirium. Finally, a relevant disagreement concerns the timeframe when increased symptoms should occur to configure a sundowning. Most of available definitions include only the occurrence or worsening of behavioral disturbances during the late afternoon and early evening $(9,10)$, whereas other researchers also consider NPS occurring throughout the night (11) or more vaguely emerging with darkness (12). It is noteworthy that some authors even question the existence of the sundown syndrome, hypothesizing that symptoms occurring during the entire day may simply be more burdening for nursing staff and caregivers in late afternoon and evening (13).

As result of the lack of consensus around the definition of sundowning, differently from other neuropsychiatric syndromes occurring among elderly individuals (e.g., delirium), no standardized criteria have been formulated for its diagnosis [e.g., the sundown syndrome does not appear in the recent fifth revision of the Diagnostic and Statistical Manual of Mental Disorders (14)].

\section{RELEVANCE OF SUNDOWNING}

Beyond the above-mentioned need of agreed definitions, sundowning is a relevant clinical phenomenon. First of all, it represents a common manifestation among people with dementia. The available studies on the topic have reported prevalence rates widely ranging between $2.5 \%$ and $66 \%$ depending on the study setting, the adopted operationalizations, and the underlying clinical diseases $(6,15)$. Sundowning has been observed to represent the second most common type of disruptive behavior in institutionalized patients with dementia after wandering and has been frequently described as "endemic" in nursing homes hosting cognitively impaired older subjects $(8,16)$. At the same time, it has also been commonly described among community-dwelling individuals with dementing illnesses [e.g., in the $66 \%$ of patients with Alzheimer's disease (AD) living at home (17)]. Based on the data from the Alzheimer's Association, as many as $20 \%$ of patients diagnosed with AD may experience a sundown syndrome (18). This phenomenon has been also reported in the context of non-AD dementias (e.g., vascular dementias, frontotemporal dementias, Lewy body dementias). Nevertheless, the scarcity of epidemiological data does not allow to properly explore the different prevalence of sundowning in the specific dementia conditions. Along the same lines, there are no consistent data concerning its prevalence according to the age, sex, and race of patients, whereas the severity of cognitive impairment has been repeatedly recognized as important predisposing factor in its development $(7,8)$. Finally, some data suggest a different seasonal occurrence of sundowning, with an observed higher incidence in the fall or winter months (10).

The relevance of the sundown syndrome also relies on its association with several adverse outcomes among people with dementia and their families. Sundowning has been indicated as a common cause of institutionalization of older demented patients. It poses a significant social and economic burden in terms of recurrent hospitalizations, prolonged hospital stay, and functional decline $(1,15)$, and it has also been associated with a faster progression of cognitive worsening in AD (19). Moreover, a relationship between its occurrence and the perceived stress of caregivers assisting $\mathrm{AD}$ patients has been demonstrated (17). Behavioral disruptions in the late afternoon or in the evening may pose a further specific challenge to caregivers who have to handle such symptoms at the end of the day, when they may be particularly fatigued. Some sundown behaviors may prevent 
patients from sleeping well, making them more likely to wander, thus increasing the risk for caregiver sleepiness and burnout $(20,21)$. A "stressed caring" of a burdened and fatigued caregiver may, in turn, lead to act wrong management strategies and increase the likelihood of an exacerbation of NPS exhibited by the patient, thus triggering a potential dangerous loop (22).

Based on these considerations, there is a growing consensus around the need of achieving a better understanding of sundowning and developing effective strategies for its management.

\section{PATHOPHYSIOLOGY OF SUNDOWNING}

The pathophysiology of sundowning is, to date, poorly defined since no causative factor has been clearly identified. Nevertheless, several hypotheses have been proposed in order to explain this phenomenon. Overall, the current conception of the sundown syndrome is that of a multifactorial phenomenon, with multiple and interacting factors (resumed in Table 1) contributing to its occurrence and main phenotypic characteristics.

Under a neurobiological perspective, a large body of evidence, from both animal (23) and human studies (24, 25), has been focused on the pathogenic role of primary alterations of the normal circadian rhythm (15). Circadian rhythm disorders have been linked with the involvement/alteration of the suprachiasmatic nucleus (SCN), located in the hypothalamus and considered as the major circadian pacemaker of the human body. Several studies have shown that volume, morphology, and activity of the SCN may be influenced by several factors, such as age, gender, and pathological conditions. A decrease in cell number

TABLE 1 | Factors that have been associated with the pathophysiology and clinical occurrence of sundowning among persons with dementia.

Neurobiological factors Degeneration of the suprachiasmatic nucleus Decreased melatonin production Disruption of circadian rhythms Impaired cholinergic neurotransmission Dysregulation of the HPA axis

\begin{tabular}{|c|c|}
\hline Pharmacological factors & $\begin{array}{l}\text { Antipsychotics } \\
\text { Anticholinergics } \\
\text { Antidepressants } \\
\text { Hypnotics }\end{array}$ \\
\hline Physiological factors & $\begin{array}{l}\text { Fatigue } \\
\text { Hunger } \\
\text { Unmet physical or psychological needs } \\
\text { Temporal changes in body temperature } \\
\text { Circadian modifications of blood glucose levels } \\
\text { Circadian changes in blood pressure }\end{array}$ \\
\hline Medical factors & $\begin{array}{l}\text { Sleep disorders } \\
\text { Sensory deprivation } \\
\text { Pain } \\
\text { Mood disorders and fluctuations } \\
\text { Cognitive deficits (e.g., agnosia) }\end{array}$ \\
\hline Environmental factors & $\begin{array}{l}\text { Exposure to inadequate amount of light } \\
\text { Lower staff-patients ratio in residential facilities } \\
\text { Lessened availability of home caregivers } \\
\text { Caregiver fatigue } \\
\text { Environmental overstimulation (noise and chaos) }\end{array}$ \\
\hline
\end{tabular}

and volume of the nucleus has been documented within the physiological aging process, especially between 80 and 100 years of age, as well as in patients with various neurodegenerative diseases (26). Neuropathological studies on AD patients have, in fact, documented relevant damages involving the SCN, mostly consisting of neuronal loss and accumulation of neurofibrillary tangles (27), while amyloid plaques are more rarely observed. The SCN of individuals with severe AD is also characterized by reactive gliosis in response to neuronal loss, with an increase in the astrocyte/neuron ratio. This damage involves both neurotensin and vasopressin neurons $(26,28)$. It has been thus hypothesized that sundowning (and other disruptive behaviors) may be the result of specific neuropathological abnormalities that interfere with normal circadian rhythm and behavioral regulation. An important component of circadian rhythm regulation is melatonin, a hormone secreted by the pineal gland in response to darkness, whose production and release is regulated by the SCN itself. Melatonin levels have been shown to decrease during aging and to be even more reduced in $\mathrm{AD}$ and other neurodegenerative diseases $(29,30)$. These findings have provided the rationale for the supplementation of melatonin in patients with clinical manifestations of disrupted sleep and circadian rhythm (31). The degeneration of the cholinergic system has also been indicated as a potential underlying mechanism of sundowning in $\mathrm{AD}$. In fact, it has been demonstrated that the SCN receive several cholinergic projections arising from the cholinergic forebrain and brain stem nuclei. Moreover, it is sensitive to cholinergic stimulation as demonstrated by the expression of muscarinic acetylcholine receptors both in SCN neurons and astroglial cells (32). Thus, it may be hypothesized that the impaired cholinergic transmission may contribute to the disruption of circadian rhythms and the emergence of behavioral disturbances. Finally, dysregulations of the hypothalamic-pituitary-adrenal axis have been related to the pathogenesis of sundowning in AD. Specifically, patients with $\mathrm{AD}$ exhibiting a sundown syndrome were shown to have significantly higher cortisol levels than those without sundowning (33).

Diverse environmental determinants may contribute to the onset of sundowning. In particular, a lessened light exposure during the day, the reduced availability of caregivers or nursing staff members during late afternoon and evening, afternoon fatigue (e.g., due to intense activity during the day), the absence of a daily routine have been all associated with an overall worsening of NPS and the emergence of a sundown syndrome (8, $9,34)$. In parallel, various medical conditions (e.g., pain, visual and/or hearing impairment, mood disorders) and medications (e.g., antidepressants, antipsychotics, dopaminergic therapies) may induce or exacerbate evening agitation and other behavioral disruptions $(8,15)$.

\section{CLINICAL APPROACH TO SUNDOWNING}

Given the multiplicity of factors and determinants potentially involved in the emergence of sundowning, a multidimensional approach to this syndrome should be adopted. In particular, special attention should be devoted to the identification of potentially treatable/reversible underlying conditions in order to timely implement targeted interventions. As already proposed for 
other NPS, integrated, multistep approaches $(4,35,36)$ should be adopted in screening, identifying, and managing sundowning.

In most of cases, the occurrence of sundowning is easily established through direct observation of patients (when institutionalized) or interviews to caregivers. History taking should be followed by a general physical examination, which should mostly be finalized at determining the presence of potentially contributing/precipitating somatic conditions (e.g., pain, sensory deprivation). Accordingly, a careful evaluation of potential environmental (e.g., lighting, noise levels, changes in daily routine) and iatrogenic triggers should be carried out. The diagnosis of sundowning is, thus, essentially clinical. Laboratory tests and neuroimaging studies may be performed when other causes of behavioral disruptions are suspected (e.g., delirium, cerebrovascular events). However, temporal fluctuations and patterns of symptoms, their recurrence over time, and non-acute onset should direct toward a diagnosis of a sundown syndrome (8). Moreover, the adoption of simple yet effective screening tools may support the differential diagnosis toward delirium (37). In some studies, computer devices have also been adopted to measure and quantify the diverse clinical manifestations among "sundowners" (e.g., locomotor activity, vocalizations) $(38,39)$. However, the use of such instruments appears difficult to be transferred in the daily clinical practice.

It is noteworthy that, to date, no dedicated tools to screen/ assess sundowning has been developed and validated. Moreover, in most of clinical tools commonly adopted in the daily practice to assess the severity of NPS [e.g., the Neuropsychiatric Inventory (40)], the temporal fluctuations of disturbances are poorly considered, so that indirect information about the eventual occurrence of sundowning could not be easily deduced. The adoption of standardized instruments to evaluate NPS may also introduce some biases, being the results, and scores potentially influenced by the personal characteristics of the interviewed caregiver and poorly reliable when such tools are administered by different raters. These aspects may have probably contributed to the poor attention so far devoted to this syndrome and might have potentially produced under-recognition of the phenomenon in the clinical setting (especially among outpatients with dementia).

\section{MANAGEMENT OF SUNDOWNING}

The management of sundowning represents a challenge in the clinical approach of people with dementia. First, the temporal fluctuations of symptoms as well as the heterogeneity of potential triggers/precipitants may complicate the identification and implementation of targeted and personalized interventions. Moreover, there are currently neither available guidelines nor placebo-controlled randomized trials concerning the treatment of such behavioral syndrome. Most of the available data come from case series or isolated case reports that, in most of cases, do not describe the medium- and long-term effectiveness of the adopted treatments. The treatment of sundowning may rely on the use of off-label pharmacological treatments, whose efficacy and safety profiles are still questioned and debated (4), and may result in polypharmacy and in an increased risk of psychotropic medication misuse. Based on these considerations, similarly to the other NPS, a growing consensus is being reached in considering non-pharmacological approaches as first-line treatments, limiting pharmacotherapies to non-responsive cases (35).

The studies that have so far explored the efficacy of nonpharmacological and pharmacological interventions specifically targeting sundowning in dementia are described in Table 2. Isolated case reports and researches not explicitly focusing on the sundown syndrome (i.e., more broadly referring to sleep-wake disturbances, agitation, nocturnal behavioral disruptions) were not included in the table.

\section{Non-Pharmacological Interventions}

Individually tailored non-pharmacological approaches should be considered as the first-line therapy for sundowning. In particular, environmental modifications have been reported to be potentially beneficial to reduce sundown-related behavioral disorders. Among these, light therapy (i.e., the exposition to bright light during the afternoon/evening hours) has been observed to produce a significant reduction of sundowning episodes (41) and motor restless behaviors (42) in open-label studies conducted on patients with dementia, as well as to improve agitated behaviors in institutionalized elderly individuals (43). Nevertheless, no RCT selectively investigating the efficacy of light therapy on sundowning has been yet conducted. Accordingly, in a recent Cochrane systematic review on the topic, authors concluded that there is insufficient evidence to justify the use of bright light therapy for improving cognition, activities of daily living, sleep, challenging behaviors, and psychiatric disturbances in dementia (44). Beside the lack of robust supporting evidence, ensuring a gradual transition from daylight to artificial lighting may attenuate behavioral changes occurring in the late afternoon and is commonly suggested by health-care providers. Additional recommendations may include minimizing unnecessary noise (e.g., noise from visitors, loud speakers, banging of dishes, loud staff conversation), promoting the adherence to schedules and stable daily routines, avoiding excessive sensory stimulation during the evening (both auditory and visual), discouraging afternoon napping, and planning more challenging activities $(8,18)$. Finally, other non-pharmacological strategies that have been shown to produce significant benefits in the management of NPS in patients with dementia (e.g., music therapy, aromatherapy, caregiver education, multisensory stimulation) may potentially be effective also in reducing sundowning.

\section{Pharmacological Interventions}

Most of available evidences concerning the pharmacological management of sundowning have been focused on the clinical efficacy of melatonin supplementation (theoretically supported by the documented deregulation/reduction of melatonin production in sundowners and in animal models). To date, only three RCTs have investigated the effectiveness of melatonin in reducing agitated behaviors in patients with dementia compared to placebo, also reporting inconclusive and conflicting results (45-47). Nevertheless, these studies were not specifically designed to assess sundowning, while more widely investigating changes in sleep quality, overall daytime functioning and behavior. Thus, there is no available evidence coming from 
TABLE 2 | Experimental studies investigating the clinical effectiveness of pharmacological and non-pharmacological therapies for the management of sundowning in dementia.

\begin{tabular}{|c|c|c|c|c|c|}
\hline Reference & Study design & Study sample & Intervention & Assessment & Main outcomes \\
\hline \multicolumn{6}{|l|}{ Melatonin } \\
\hline $\begin{array}{l}\text { Fainstein et al. (48) } \\
\text { Brusco et al. (49) }\end{array}$ & Open-label & $\begin{array}{l}41 \text { elderly } \\
\text { subjects (10 with } \\
\text { Alzheimer's disease } \\
\text { (AD) and vascular } \\
\text { dementia) }\end{array}$ & 3 mg/day for 21 days & $\begin{array}{l}\text { Daily logs of sleep and } \\
\text { wake quality completed } \\
\text { by caregivers }\end{array}$ & $\begin{array}{l}\text { Significant decrease of sundown agitation in the } 70 \% \\
\text { of demented patients. Decrease of the coefficient of } \\
\text { variation of bed time between days } 0-2 \text { and days } 19-21 \\
\text { of treatment }(58.0 \pm 24.7 \text { vs } 41.5 \pm 20.9 ; p=0.03)\end{array}$ \\
\hline Brusco et al. (49) & Retrospective & $\begin{array}{l}14 \text { outpatients with } \\
\text { AD; mean MMSE } \\
\text { score: } 14.4 \pm 7.9\end{array}$ & $\begin{array}{l}9 \mathrm{mg} / \text { day for } \\
22-35 \text { months }\end{array}$ & $\begin{array}{l}\text { Daily logs of sleep and } \\
\text { wake quality completed } \\
\text { by caregivers }\end{array}$ & $\begin{array}{l}\text { Remission of sundowning } 12 \text { patients; attenuation in two } \\
\text { cases. Significant improvement of sleep quality between } \\
\text { baseline and end of treatment }(p<0.01)\end{array}$ \\
\hline $\begin{array}{l}\text { Cohen-Mansfield } \\
\text { et al. (50) }\end{array}$ & Open-label & $\begin{array}{l}11 \text { older nursing } \\
\text { home residents } \\
\text { with dementia }\end{array}$ & $3 \mathrm{mg} /$ day for 21 days & $\begin{array}{l}\text { Daily logs of sleep and } \\
\text { wake quality completed } \\
\text { by nurses, Cohen- } \\
\text { Mansfield Agitation } \\
\text { Inventory }\end{array}$ & $\begin{array}{l}\text { Significant reduction of sundown agitation between week } \\
1 \text { and } 4 \text { (physically non-aggressive behavior: } 1.92 \text { vs } \\
1.46 ; p=0.022 \text {. Verbally non-aggressive behavior: } 2.30 \\
\text { vs } 1.75 ; p=0.028 \text { ) }\end{array}$ \\
\hline Cardinali et al. (31) & Open-label & $\begin{array}{l}45 \text { outpatients } \\
\text { with } A D\end{array}$ & $\begin{array}{l}6-9 \text { mg/day for } \\
4 \text { months }\end{array}$ & $\begin{array}{l}\text { Daily logs of sleep and } \\
\text { wake quality completed } \\
\text { by caregivers }\end{array}$ & $\begin{array}{l}\text { Suppression of sundowning (regardless of the } \\
\text { concomitant medication employed to treat cognitive or } \\
\text { behavioral signs of } A D \text { ) }\end{array}$ \\
\hline Mahlberg et al. (51) & Open-label & 7 AD outpatients & 3 mg/day for 3 weeks & Actigraphy & $\begin{array}{l}\text { Remission of sundowning in four patients; attenuation in } \\
\text { two cases }\end{array}$ \\
\hline \multicolumn{6}{|l|}{ Light therapy } \\
\hline Satlin et al. (41) & Open-label & 10 AD inpatients & $\begin{array}{l}2 \mathrm{~h} / \text { day of exposure } \\
\text { to bright light between } \\
\text { 7:00 and 9:00 p.m. for } \\
1 \text { week }\end{array}$ & $\begin{array}{l}\text { Clinical observation and } \\
\text { actigraphy }\end{array}$ & Reduction of sundowning episodes \\
\hline
\end{tabular}

Only studies specifically targeting sundowning were included in the table.

ad hoc RCTs regarding the effects of melatonin supplementation in the treatment of sundowning in dementia. On the other hand, available open-label studies and case series (resumed in Table 2) have more consistently documented a reduction of sundowning episodes in most of patients with dementia receiving melatonin (31, 48-51). However, it should be noticed that some issues (e.g., influence of concomitant medications, severity of cognitive decline, characteristics of the living environment) were not properly addressed and may have biased the study findings and conclusions.

Cholinesterase inhibitors have repeatedly been shown to produce a meaningful decrease of behavioral disturbances in demented patients (52). Conflicting data (mainly coming from isolated case reports) exist about their potential role in positively influencing sleep disorders, circadian rhythm alterations, and sundown behavioral disruptions occurring in $\mathrm{AD}$ and other dementias $(53,54)$. Currently, there is no specific data concerning the treatment of sundowning with the N-methyl-D-aspartate receptor antagonist memantine.

Antipsychotics have been frequently indicated by physicians as the most commonly prescribed class of medications to manage sundowning (55). Nevertheless, there is limited information available in the medical literature on this particular topic, being most of RCTs focused on different NPS such as delusions, hallucinations, and agitation. Along the same lines, there is no evidence supporting the use of benzodiazepines and other hypnotics, whose use has been instead linked with a common paradoxical increase of behavioral disturbances.

\section{CONCLUSION AND FUTURE DIRECTIONS}

Sundowning represents a relevant and challenging manifestation of dementia, occurring in a large proportion of affected individuals and being associated with a significant social and economic burden. Increasing our knowledge on how to recognize, approach, and manage sundowning may thus consent to significantly improve the wellbeing of patients and their carers. Specifically, a greater effort is needed in order to disentangle and clarify the complex and multifaceted pathophysiological bases of this phenomenon. Moreover, dedicated screening and assessment tools should be developed and validated in order to facilitate its detection in the routine clinical practice (particularly in outpatient settings). Finally, ad hoc RCTs should be designed and conducted to investigate the effectiveness of non-pharmacological- and pharmacological-targeted strategies for its management.

\section{AUTHOR CONTRIBUTIONS}

MC and MV performed the literature search and wrote the manuscript. AT, GS, FD, and LT contributed to the conception of the article and to the review of literature. CL and GB participated to the critical appraisal of the available evidence on the topic.

\section{FUNDING}

The authors have no funding sources to disclose for the present study. 


\section{REFERENCES}

1. Herrmann N, Lanctôt KL, Sambrook R, Lesnikova N, Hébert R, McCracken P, et al. The contribution of neuropsychiatric symptoms to the cost of dementia care. Int J Geriatr Psychiatry (2006) 21(10):972-6. doi:10.1002/gps.1594

2. Dodel R, Belger M, Reed C, Wimo A, Jones RW, Happich M, et al. Determinants of societal costs in Alzheimer's disease: GERAS study baseline results. Alzheimers Dement (2015) 11(8):933-45. doi:10.1016/j. jalz.2015.02.005

3. Canevelli M, Adali N, Voisin T, Soto ME, Bruno G, Cesari M, et al. Behavioral and psychological subsyndromes in Alzheimer's disease using the Neuropsychiatric Inventory. Int J Geriatr Psychiatry (2013) 28(8):795-803. doi:10.1002/gps.3904

4. Kales HC, Gitlin LN, Lyketsos CG; Detroit Expert Panel on Assessment and Management of Neuropsychiatric Symptoms of Dementia. Management of neuropsychiatric symptoms of dementia in clinical settings: recommendations from a multidisciplinary expert panel. J Am Geriatr Soc (2014) 62(4):762-9. doi:10.1111/jgs. 12730

5. Cameron D. Studies in senile nocturnal delirium. Psychiatr Q (1941) 15:47-53. doi:10.1007/BF01613953

6. Evans LK. Sundown syndrome in institutionalized elderly. J Am Geriatr Soc (1987) 35(2):101-8. doi:10.1111/j.1532-5415.1987.tb01337.x

7. Little JT, Satlin A, Sunderland T, Volicer L. Sundown syndrome in severely demented patients with probable Alzheimer's disease. J Geriatr Psychiatry Neurol (1995) 8(2):103-6. doi:10.1177/089198879500800205

8. Khachiyants N, Trinkle D, Son SJ, Kim KY. Sundown syndrome in persons with dementia: an update. Psychiatry Investig (2011) 8(4):275-87. doi:10.4306/ pi.2011.8.4.275

9. Bedrosian TA, Nelson RJ. Sundowning syndrome in aging and dementia: research in mouse models. Exp Neurol (2013) 243:67-73. doi:10.1016/ j.expneurol.2012.05.005

10. Volicer L, Harper DG, Manning BC, Goldstein R, Satlin A. Sundowning and circadian rhythms in Alzheimer's disease. Am J Psychiatry (2001) 158(5):704-11. doi:10.1176/appi.ajp.158.5.704

11. Bliwise DL, Watts RL, Watts N, Rye DB, Irbe D, Hughes M. Disruptive nocturnal behavior in Parkinson's disease and Alzheimer's disease. J Geriatr Psychiatry Neurol (1995) 8(2):107-10. doi:10.1177/089198879500800206

12. Bliwise DL. What is sundowning? J Am Geriatr Soc (1994) 42(9):1009-11. doi:10.1111/j.1532-5415.1994.tb06598.x

13. Bliwise DL, Carroll JS, Lee KA, Nekich JC, Dement WC. Sleep and "sundowning" in nursing home patients with dementia. Psychiatry Res (1993) 48(3):277-92. doi:10.1016/0165-1781(93)90078-U

14. American Psychiatric Association. Diagnostic and Statistical Manual of Mental Disorders: DSM-5. 5th ed. Arlington, VA: American Psychiatric Association (2013).

15. Gnanasekaran G. "Sundowning" as a biological phenomenon: current understandings and future directions: an update. Aging Clin Exp Res (2016) 28(3):383-92. doi:10.1007/s40520-015-0431-3

16. U.S. Congress, Office of Technology Assessment. Special Care Units for People with Alzheimer's and Other Dementias: Consumer Education, Research, Regulatory, and Reimbursement Issues. Washington, DC: Government Printing Office (1992).

17. Gallagher-Thompson D, Brooks JO, Bliwise D, Leader J, Yesavage JA. The relations among caregiver stress, "sundowning" symptoms, and cognitive decline in Alzheimer's disease. JAm Geriatr Soc (1992) 40(8):807-10. doi:10.1111/j.1532-5415.1992.tb01853.x

18. Sundowning, Sleep, Alzheimer's \& Dementia. Alzheimer's Association. (2016). Available from: http://www.alz.org/care/alzheimers-dementia-sleep-issues-sundowning.asp

19. Scarmeas N, Brandt J, Blacker D, Albert M, Hadjigeorgiou G, Dubois B, et al. Disruptive behavior as a predictor in Alzheimer disease. Arch Neurol (2007) 64(12):1755-61. doi:10.1001/archneur.64.12.1755

20. Matsumoto N, Ikeda M, Fukuhara R, Shinagawa S, Ishikawa T, Mori T, et al. Caregiver burden associated with behavioral and psychological symptoms of dementia in elderly people in the local community. Dement Geriatr Cogn Disord (2007) 23(4):219-24. doi:10.1159/000099472

21. Pollak CP, Perlick D. Sleep problems and institutionalization of the elderly. J Geriatr Psychiatry Neurol (1991) 4(4):204-10. doi:10.1177/ 089198879100400405
22. de Vugt ME, Stevens F, Aalten P, Lousberg R, Jaspers N, Winkens I, et al. Do caregiver management strategies influence patient behaviour in dementia? Int J Geriatr Psychiatry (2004) 19(1):85-92. doi:10.1002/ gps.1044

23. Huitrón-Reséndiz S, Sánchez-Alavez M, Criado JR. Sleep-wake states in transgenic mouse models overexpressing the human beta-amyloid precursor protein. Am J Alzheimers Dis Other Demen (2005) 20(2):87-90. doi:10.1177/153331750502000204

24. Harper DG, Volicer L, Stopa EG, McKee AC, Nitta M, Satlin A. Disturbance of endogenous circadian rhythm in aging and Alzheimer disease. Am J Geriatr Psychiatry (2005) 13(5):359-68. doi:10.1097/00019442-20050500000004

25. Satlin A, Volicer L, Stopa EG, Harper D. Circadian locomotor activity and core-body temperature rhythms in Alzheimer's disease. Neurobiol Aging (1995) 16(5):765-71. doi:10.1016/0197-4580(95)00059-N

26. Swaab DF, Fliers E, Partiman TS. The suprachiasmatic nucleus of the human brain in relation to sex, age and senile dementia. Brain Res (1985) 342(1):37-44. doi:10.1016/0006-8993(85)91350-2

27. Stopa EG, Volicer L, Kuo-Leblanc V, Harper D, Lathi D, Tate B, et al. Pathologic evaluation of the human suprachiasmatic nucleus in severe dementia. J Neuropathol Exp Neurol (1999) 58(1):29-39. doi:10.1097/00005072-199901000-00004

28. Zhou JN, Hofman MA, Swaab DF. VIP neurons in the human SCN in relation to sex, age, and Alzheimer's disease. Neurobiol Aging (1995) 16(4):571-6. doi:10.1016/0197-4580(95)00043-E

29. Liu RY, Zhou JN, van Heerikhuize J, Hofman MA, Swaab DF. Decreased melatonin levels in postmortem cerebrospinal fluid in relation to aging, Alzheimer's disease, and apolipoprotein E-epsilon4/4 genotype. JClin Endocrinol Metab (1999) 84(1):323-7. doi:10.1210/jc.84.1.323

30. Srinivasan V, Pandi-Perumal SR, Cardinali DP, Poeggeler B, Hardeland R. Melatonin in Alzheimer's disease and other neurodegenerative disorders. Behav Brain Funct (2006) 2:15. doi:10.1186/1744-9081-2-15

31. Cardinali DP, Brusco LI, Liberczuk C, Furio AM. The use of melatonin in Alzheimer's disease. Neuro Endocrinol Lett (2002) 23(Suppl 1):20-3.

32. Hut RA, Van der Zee EA. The cholinergic system, circadian rhythmicity, and time memory. Behav Brain Res (2011) 221(2):466-80. doi:10.1016/ j.bbr.2010.11.039

33. Venturelli M, Scarsini R, Muti E, Salvagno GL, Schena F. Sundowning syndrome and hypothalamic-pituitary-adrenal axis dysregulation in individuals with Alzheimer's disease: is there an association? J Am Geriatr Soc (2013) 61(11):2055-6. doi:10.1111/jgs.12491

34. McGaffigan S, Bliwise DL. The treatment of sundowning. A selective review of pharmacological and nonpharmacological studies. Drugs Aging (1997) 10(1):10-7. doi:10.2165/00002512-199710010-00002

35. Gitlin LN, Kales HC, Lyketsos CG. Nonpharmacologic management of behavioral symptoms in dementia. JAMA (2012) 308(19):2020-9. doi:10.1001/ jama.2012.36918

36. Clair KL, PiecesHome. P.I.E.C.E.S - Putting the Pieces Together. (2016). Available from: http://pieceslearning.com/

37. Hendry K, Quinn TJ, Evans J, Scortichini V, Miller H, Burns J, et al. Evaluation of delirium screening tools in geriatric medical inpatients: a diagnostic test accuracy study. Age Ageing (2016) 45(6):832-7. doi:10.1093/ ageing/afw130

38. Burgio LD, Scilley K, Hardin JM, Janosky J, Bonino P, Slater SC, et al. Studying disruptive vocalization and contextual factors in the nursing home using computer-assisted real-time observation. J Gerontol (1994) 49(5):230-9. doi:10.1093/geronj/49.5.P230

39. Martin J, Marler M, Shochat T, Ancoli-Israel S. Circadian rhythms of agitation in institutionalized patients with Alzheimer's disease. Chronobiol Int (2000) 17(3):405-18. doi:10.1081/CBI-100101054

40. Cummings JL. The Neuropsychiatric Inventory: assessing psychopathology in dementia patients. Neurology (1997) 48(5 Suppl 6):S10-6. doi:10.1212/ WNL.48.5_Suppl_6.10S

41. Satlin A, Volicer L, Ross V, Herz L, Campbell S. Bright light treatment of behavioral and sleep disturbances in patients with Alzheimer's disease. Am J Psychiatry (1992) 149(8):1028-32. doi:10.1176/ajp.149. 8.1028

42. Haffmans PM, Sival RC, Lucius SA, Cats Q, van Gelder L. Bright light therapy and melatonin in motor restless behaviour in dementia: 
a placebo-controlled study. Int J Geriatr Psychiatry (2001) 16(1):106-10. doi:10.1002/1099-1166(200101)16:1<106::AID-GPS288>3.0.CO;2-9

43. Lovell BB, Ancoli-Israel S, Gevirtz R. Effect of bright light treatment on agitated behavior in institutionalized elderly subjects. Psychiatry Res (1995) 57(1):7-12. doi:10.1016/0165-1781(95)02550-G

44. Forbes D, Blake CM, Thiessen EJ, Peacock S, Hawranik P. Light therapy for improving cognition, activities of daily living, sleep, challenging behaviour, and psychiatric disturbances in dementia. Cochrane Database Syst Rev (2014) 2:CD003946. doi:10.1002/14651858.CD003946.pub4

45. Asayama K, Yamadera H, Ito T, Suzuki H, Kudo Y, Endo S. Double blind study of melatonin effects on the sleep-wake rhythm, cognitive and non-cognitive functions in Alzheimer type dementia. JNippon Med Sch Nippon Ika Daigaku Zasshi (2003) 70(4):334-41. doi:10.1272/jnms. 70.334

46. Gehrman PR, Connor DJ, Martin JL, Shochat T, Corey-Bloom J, Ancoli-Israel S. Melatonin fails to improve sleep or agitation in double-blind randomized placebo-controlled trial of institutionalized patients with Alzheimer disease. Am J Geriatr Psychiatry (2009) 17(2):166-9. doi:10.1097/JGP. 0b013e318187de18

47. Singer C, Tractenberg RE, Kaye J, Schafer K, Gamst A, Grundman M, et al. A multicenter, placebo-controlled trial of melatonin for sleep disturbance in Alzheimer's disease. Sleep (2003) 26(7):893-901.

48. Fainstein I, Bonetto AJ, Brusco LI, Cardinali DP. Effects of melatonin in elderly patients with sleep disturbance: a pilot study. Curr Ther Res (1997) 58(12):990-1000. doi:10.1016/S0011-393X(97)80066-5

49. Brusco LI, Fainstein I, Márquez M, Cardinali DP. Effect of melatonin in selected populations of sleep-disturbed patients. Biol Signals Recept (1999) 8(1-2):126-31. doi:10.1159/000014580

50. Cohen-Mansfield J, Garfinkel D, Lipson S. Melatonin for treatment of sundowning in elderly persons with dementia - a preliminary study. Arch Gerontol Geriatr (2000) 31(1):65-76. doi:10.1016/S0167-4943(00)00068-6
51. Mahlberg R, Kunz D, Sutej I, Kühl K-P, Hellweg R. Melatonin treatment of day-night rhythm disturbances and sundowning in Alzheimer disease: an open-label pilot study using actigraphy. J Clin Psychopharmacol (2004) 24(4):456-9. doi:10.1097/01.jcp.0000132443.12607.fd

52. Campbell N, Ayub A, Boustani MA, Fox C, Farlow M, Maidment I, et al. Impact of cholinesterase inhibitors on behavioral and psychological symptoms of Alzheimer's disease: a meta-analysis. Clin Interv Aging (2008) 3(4):719-28. doi:10.2147/CIA.S4250

53. Skjerve A, Nygaard HA. Improvement in sundowning in dementia with Lewy bodies after treatment with donepezil. Int J Geriatr Psychiatry (2000) 15(12):1147-51. doi:10.1002/1099-1166(200012)15:12<1147::AID-GPS262> 3.0.CO;2-L

54. Rogers SL, Doody RS, Mohs RC, Friedhoff LT. Donepezil improves cognition and global function in Alzheimer disease: a 15-week, double-blind, placebo-controlled study. Donepezil Study Group. Arch Intern Med (1998) 158(9):1021-31. doi:10.1001/archinte.158.9.1021

55. Stoppe G, Sandholzer H, Staedt J, Winter S, Kiefer J, Rüther E. Sleep disturbances in the demented elderly: treatment in ambulatory care. Sleep (1995) 18(10):844-8.

Conflict of Interest Statement: The authors declare that the research was conducted in the absence of any commercial or financial relationships that could be construed as a potential conflict of interest.

Copyright $\odot 2016$ Canevelli, Valletta, Trebbastoni, Sarli, D’Antonio, Tariciotti, de Lena and Bruno. This is an open-access article distributed under the terms of the Creative Commons Attribution License (CC BY). The use, distribution or reproduction in other forums is permitted, provided the original author(s) or licensor are credited and that the original publication in this journal is cited, in accordance with accepted academic practice. No use, distribution or reproduction is permitted which does not comply with these terms. 